\title{
Application of Ordinal Logistic Regression Analysis in Determining Risk Factors of Active Trachoma among Rural Children of Aged 1-9 Years Old in Kaffa Zone, South West Ethiopia
}

\author{
Tesfaledet Tsegay ${ }^{1,{ }^{*}, Y e w u l s h e t ~ M e n g i s t u ~}{ }^{2}$,Tadesse Nigussie $^{3}$ \\ ${ }^{1}$ Msc in Biostatistics, Department of Statistics, Mizan Tepi University, Ethiopia \\ ${ }^{2}$ Msc in Biostatistics, Department of Statistics, Mizan Tepi University, Ethiopia \\ ${ }^{3}$ MPH in Reproductive Health, Department of Public Health, Mizan Tepi University, Ethiopia
}

*Corresponding Author: Tesfaledet Tsegay, Msc in Biostatistics, Department of Statistics, Mizan Tepi University, Ethiopia, Email: tesfa.tsegay@gmail.com

\begin{abstract}
Trachoma is the leading infectious causes of blindness worldwide and most common problem in developing countries including Ethiopia. This study aims to identify the determinants factor of active trachoma among rural children of aged [1-9] years old in Kaffa zone, south west Ethiopia. The study was conducted rural part of Kaffa zone children aged of 1-9 years old. A cross sectional community-based survey was conducted. A total of 754 children were assessed for signs of trachoma. Trachoma grading was done by ophthalmic nurses following the WHO grading system. From the sampled children $26.9 \%$ of them have moderately active trachoma, 3.7\% of them have severely active trachoma, and the rest $69.4 \%$ of the children was no active trachoma. The ordinal logistic regression model show that Child age, Cattle in the house, Face washing frequency per a day, Number of person sharing room, Fly density and Type of garbage disposal were most important determinants for active trachoma status of children 1-9 years of age in the rural area Kaffa Zone.Finally our result indicate increase washing frequency per day and use pit with cover for garbage disposal and living in separate room with cattle was protect a child from active trachoma. In contrary younger children, living in crowded environment and having fly around child's face increase a risk of active trachoma. The current study thus helps provide a better understanding of the events linked to these diseases at the local level and the basis for establishing specific programs for their control.
\end{abstract}

Keywords: Active Trachoma, Ordinal Logistic Regression, South west Ethiopia

\section{INTRODUCTION}

Trachoma is the leading infectious cause of blindness worldwide and most common problem in developing countries including Ethiopia. It is caused by repeated infection with eye strain of bacteria called Chlamydia Trachomasis. It is transmitted by bacterium direct spread of infected ocular material from one person to another Transmission occurs due to overcrowding especially within-households. The spread of trachoma is by eye-seeking flies (Musca sorbens), direct contacts, fingers and form its which lay its eggs on exposed human faces [1].

Trachoma is the major cause of preventable blindness in many under privileged communities of developing countries. It is an infectious disease occurring in community with poor hygiene and inadequate sanitation. The environmental risk factors that facilitate transmission include dry and dirty home environment, and discharge (on face, eyes, nose and ears) from infected individual [2].

According to the WHO report, globally close to 1.3 million people are blind due to trachoma, while about 84 million people suffer from active trachoma (Trachomatous inflammation follicular (TF) and/or Trachomatous inflammation intense (TI)). Active infection is mostly seen in young children with a peak incidence of around four to six years, while subsequent causes blindness [1].

Most studies done on trachoma among children were urban and institutional based studies which may not assess risk factors with in rural 
community where the children come from [3]. This study investigate social, personal and environmental risk factors of active trachoma among rural children with-in community.

Trachoma cannot be tackled without understanding its causes; there is also inconsistency across studies regarding the determinants factor behind the prevalence of trachoma among rural children therefore that is why this study is crucial to assess the prevalence of active trachoma and identify underling factors of trachoma among rural children in Kaffa zone. Therefore, the main aim of this study was to assess the prevalence and risk factors of active trachoma among rural children of aged 1-9 years old in Kaffa zone, south west Ethiopia.

\section{Material And Methods}

The study was community - based, crosssectional study design. House to house survey was employed to identify children with signs of active trachoma that was conducted by trained health professionals. A pre-tested quantitatively designed questionnaire was employed to collect important information about demographic, environmental and behavioral factors.

The study area is located in Kaffa zone, one of the 13 zones in the EthiopianSouthern Nations, Nationalities, and Peoples' Region (SNNPR). Kaffa is bordered on the south by Debub Omo, on the southwest by Bench Maji, on the west by Sheka, on the north by the Oromia Region, and on the east by Konta. Gojeb River runs along part of the northern border of this zone. The administrative center of Kaffa is Bonga. The zone has 10 woreda with a total population of 874,716 projected from 2011 census report [26]. The larger proportion of the population lives in the rural area and children of age below $10 \mathrm{yrs}$. There are about 175,967 households in the rural area. The source of population was children age of 1-9 years old because active trachoma is very common in small children than any other segment of the population. Children aged $1-9$ years of age are reservoir of trachoma infection, and active trachoma prevalence studies are recommended to be studied in this age group [27].

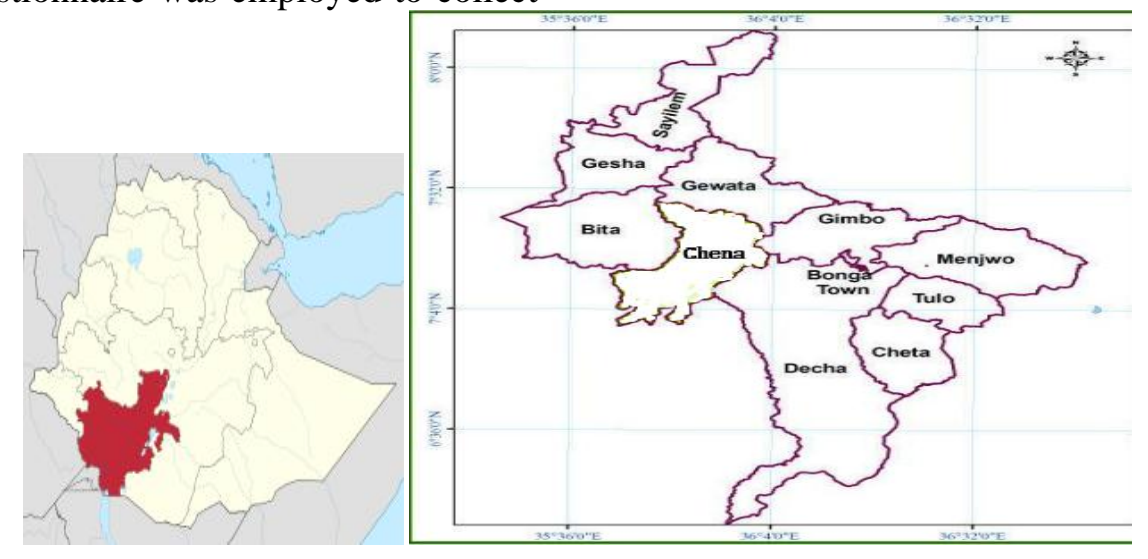

Figure1. Geographical map study zone

Children of age 1- 9 years living in the rural part of Kaffa zone was included as the source population. The 10 Woreda of the zone were categorized in the three agro climatic regions low altitude (Kolla), medium altitude (WoinaDega) and high altitude (Dega). Woreda were categorized in to one of the divisions based on where the larger proportion of the area lies. One woreda was selected randomly from each agro climatic zone.

The sample size for this study was calculated using a single population proportion formula including the following parameters: $40.1 \%$ prevalence of active trachoma (either TF or TI) for children in the age group 1 - 9 years [Yemane et al. (2007)], 95\% confidence interval and 5\% marginal error (d). As a multistage sampling techniques employed to identify the study subject, the default value of design effect (deff), should be set as 2.0 unless there is supporting empirical data from previous or related surveys that suggest a different value [CSA,2003]. Also $10 \%$ was added nonresponse. Thus the final sample size was 812 .

From each selected woreda respective one representative kebeles were included in the study by random selection. List of the households will the base for identifying sample households by systematic selection. All children of age 1-9 years residing in selected households will eligible for the study. The total of 812 households from the selected three kebeles, 
were visited to get the required number of study children. From each agro climatic zone sample was selected proportionally 222 from Kola, 379 houses from Woina-Dega and 192 houses from Dega kebeles were study households Those households where there were no eligible children were excluded from the study. The sample selection procedure is described schematically as follows (Figure 2).

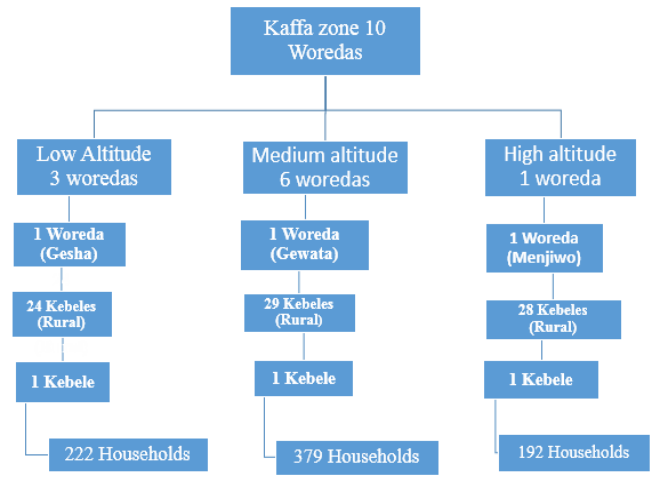

Figure2. Schematic Presentation of Sample Selection Procedure

Primary data was used for this study. Interview using structured questionnaire and physical eye examination was used to collect important primary data on socio-economic, demographic and health characteristics. Examination of child eye will be done by twelve nurses especially trained for eye care. The questionnaire is prepared in English language and then translated into Amharic language. To ensure the comparability of the information pre-test of the questionnaire was done among 1-9 rural children in Bita Woreda. Twelve ophthalmic nurses and fifteen enumerators was assigned to perform eye examination and collecting relevant data from each sampled home visit. From each selected home if there will be more than one child it was selected by lottery method.

\subsection{Eye Examination}

Agreement level on grading examination results among graders was measured taking the ophthalmologist as a gold standard and it was found to be greater than $85 \%$. Immediately after the training, health professionals went to the field to perform eye examination on selected study children. Examination of each eye separately by starting with the right eye using magnifying loupe (binocular loupe) was done at each sampled home. The examiner was clean his hands with alcohol between each examination. The guide used for reporting examination result was the simplified trachoma grading scheme, which was developed by WHO for field work. The child's face assessment was carried out before the trachoma examination for face cleanness, discharge and flies on the face. Children eye examination was done using instrument. The trachoma grader wearing $2.5 \mathrm{x}$ loupes and torch assessed each eye for the active trachoma using the WHO simplified grading scheme.

\subsection{Dependent Variables}

The response variable in this study is the ordinal response variable status active trachoma which is categorized as: not active trachoma (neither TF nor TI), moderately active trachoma (only $\mathrm{TF}$ ) or severely active trachoma. So, each child that participated in this study is classified as whether he or she is no active trachoma, moderately active trachoma or severe sign of active trachoma.

\subsection{Ordinal Logistic Regression}

There are several occasions when the outcome variable is polytomous. Such outcome variable can be classified into two, multinomial and ordinal. A number of logistic regression models have been developed for analyzing ordinal response variables. These include the proportional odds model (POM), two versions of the partial proportional odds model-without restrictions (PPOM-UR) and with restrictions (PPOM - R), continuous ratio model (CRM), and stereotype model (SM). The most frequently used ordinal logistic regression model in practice is the constrained cumulative logit model called the proportional odds model The POM is widely used in epidemiological and biomedical applications but requires strong assumptions that may lead to incorrect interpretations if the assumptions are violated [4].

The PO model has some appealing features. At first, it is invariant under several categories as only the signs of the regression coefficients change when the $Y$ codes are inverted (i.e., $Y_{1}$ is coded as $Y_{k}, Y_{2}$ as $Y_{k-1}$ and so on). Secondly, it is invariant under collapsibility of the ordered categories as the regression coefficients do not change when response categories are collapsed or the category definitions are changed. Thirdly, it produces the most easily interpretable regression coefficients as $\exp (-\beta)$ is the homogenous odds ratio over all cut-off points summarizing the effects of the explanatory factor $\mathrm{X}$ on the response $\mathrm{Y}$ in one single frequently used measure. Due to these reasons, 
the PO model is by far the most used regression model for ordinal data. Let $\mathrm{Y}$ be the categorical variable with $\mathrm{C}$ ordered categories. Cumulative probability reflects the ordering with:

$\operatorname{Pr}(\mathrm{Y} \leq 1) \leq \operatorname{pr}(\mathrm{Y} \leq 2) \leq \ldots \leq \operatorname{pr}(\mathrm{Y} \leq \mathrm{c})=1$ Let, $\pi_{\mathrm{i}}=\operatorname{Pr}(\mathrm{Y} \leq \mathrm{i}), \quad \mathrm{i}=1, \ldots, \mathrm{c}-1$

Then the odds of the first $i$ cumulative probability are:

$$
\begin{aligned}
\operatorname{odds}(Y \leq \mathrm{i})= & \frac{\operatorname{pr}(\mathrm{Y} \leq \mathrm{i})}{1-\operatorname{pr}(\mathrm{Y} \leq \mathrm{i})}=\left[\frac{\pi_{\mathrm{i}}}{1-\pi_{\mathrm{i}}}\right], \mathrm{i} \\
& =1,2, \ldots, \mathrm{c}-1
\end{aligned}
$$

The POM models the log-odds (logits) of the first i cumulative probabilities as:

$\operatorname{logit}[\mathrm{Y} \leq \mathrm{i}]=\log \left[\frac{\pi_{\mathrm{i}}}{1-\pi_{\mathrm{i}}}\right]=\log \left[\frac{\pi_{i}}{\pi_{i+1}+\ldots+\pi_{c}}\right], i=$ $1,2, \ldots, c-1$

Consider a collection of Pexplanatory variables for the $\boldsymbol{l}^{\text {th }}$ subject denoted by the vector $\boldsymbol{X}_{\boldsymbol{l}}^{\prime}=$ $\left(x_{1 l}, x_{2 l}, \ldots, x_{p l}\right), \boldsymbol{l}=1,2, \ldots, n$. The relationship between the predictor and response variables is not linear in logistic regression. Instead, the logistic regression function, which is the logit transformation of $\pi_{i}\left(X_{l}\right)$ is used:

$$
\begin{gathered}
\pi_{i}\left(X_{l}\right)=\operatorname{Pr}\left(Y_{l} \leq i \mid X_{l}\right)=\frac{e^{\left(\alpha_{i}-\beta_{1} x_{1 l^{-}} \ldots-\beta_{p} x_{p l}\right)}}{1+e^{\left(\alpha_{i}-\beta_{1} x_{1 l^{-}} \ldots-\beta_{p} x_{p l}\right)}} \\
=\frac{e^{\left(\alpha_{i}-X_{l}^{\prime} \beta\right)}}{1+e^{\left(\alpha_{i}-X_{l}^{\prime} \beta\right)}} \\
i=1,2, \ldots, c-1 ; l=1,2, \ldots, n
\end{gathered}
$$

Where $\beta$ is a column vector of $\mathrm{P}$ regression coefficients and $\alpha_{i}$ is $\boldsymbol{i}^{t h}$ intercept coefficient.

Then the logit or log-odds of the first $i$ cumulative probabilities is modeled as a linear function of the explanatory variables as:

$$
\begin{aligned}
& \operatorname{logit}\left[Y_{\boldsymbol{l}} \leq i \mid x_{\boldsymbol{l}}\right]=\log \left[\frac{\pi_{i}\left(X_{l}\right)}{1-\pi_{i}\left(X_{l}\right)}\right] \\
& \begin{aligned}
=\alpha_{i}-\beta_{1} x_{1 l}- & \ldots-\beta_{p} x_{p l}=\alpha_{i}-\boldsymbol{X}_{l}^{\prime} \beta \quad \text { fori } \\
& =1,2, \ldots, c-1 ; l=1,2, \ldots, n
\end{aligned}
\end{aligned}
$$

\subsection{Data Analysis}

The analysis is carried out in two sections. In the first section, results of descriptive statistics are presented; in the second section, we identified and examined the determinants of active trachoma among 1-9 years old rural children using ordinal logistic regression with the help IBM SPSS statistics 20.

\section{RESULTS AND DISCUSSION}

A total of 754 rural children aged 1-9 years old were selected from the target population out of ARC Journal of Public Health and Community Medicine which $69.4 \%, 26.9 \%$ and $3.7 \%$ are have no active trachoma, moderately active trachoma and severely active trachoma, respectively. So out of total sample children $30.6 \%$ have active trachoma (TF and TI) in the study area.

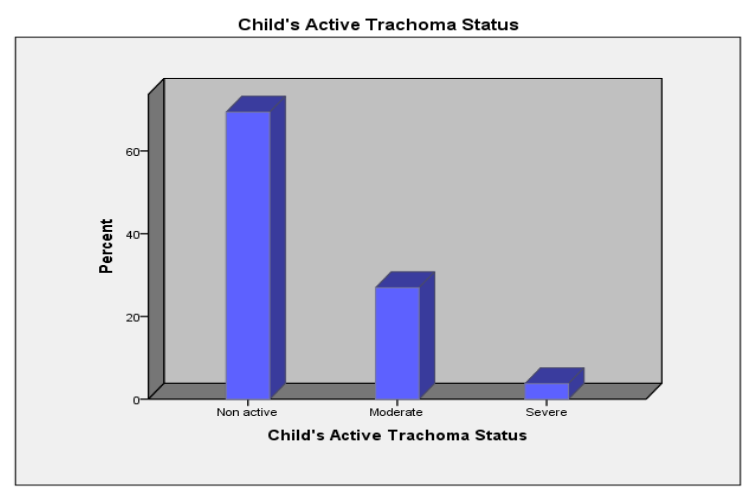

Figure3.1. Simple Bar chart of the rural children age of 1-9 years old active trachoma status in in Kaffa Zone, SWE

From the sampled rural children $50.1 \%$ of them are male with high prevalence of active trachoma status $27.2 \%, 7.1 \%$ of children have moderate and severe active trachoma as compared to female rural children as shown in table 4.1. The children living in the household with cattle $60 \%, 30 \%$ and $4 \%$ of them are no, moderate and severely trachoma, respectively. These proportions are $90.4 \%, 7.7 \%$ and $1.5 \%$ trachoma status for those children from households who do not live with cattle having house, respectively. Out of the children who use soap to wash their face $88.4 \%, 9.7 \%, 1.9 \%$ of them have no, moderate and severe active trachoma status. These proportions are $56.1 \%$, $39 \%$ and $5 \%$ for children who do not use soap at least one a day.

The percentage distributions of child active trachoma status differ by their face washing frequency per a day. Of the children who wash their face once a day, $45.3 \%$ have not active trachoma, $46.5 \%$ have moderate and $8 \%$ have severe trachoma status. These proportions are $88.5 \%, 11.5 \%$ and $0 \%$ for active trachoma status for children, who wash their face twice a day and $32.6 \%, 4.2 \%$ and $0 \%$ of children who wash their face more than twice per a day have the respective active trachoma status.

Table 4.1 also show that amount of water consumption per a day have also bearing on active trachoma status of children. Out of children from household using 20-50 liters per a day have $70.5 \%, 26.7 \%$ and $2.9 \%$ of them have no, moderate and severe active trachoma respectively. In contrary children from 
Application of Ordinal Logistic Regression Analysis in Determining Risk Factors of Active Trachoma among Rural Children of Aged 1-9 Years Old in Kaffa Zone, South West Ethiopia

household using less than 20 liters per a day have $53.5 \%, 39.4 \%$ and $7 \%$ no, moderate and severe active trachoma status on children respectively.

Table3.1. Children's aged 1-9 years old Active trachoma status according to selected independent variables, Kaffa zone, South-West Ethiopia (2018).

\begin{tabular}{|c|c|c|c|c|c|c|c|c|}
\hline \multirow[t]{2}{*}{ Variable } & \multirow[t]{2}{*}{ Categories } & \multirow{2}{*}{$\begin{array}{c}\text { Frequency } \\
(\%)\end{array}$} & \multicolumn{3}{|c|}{ Child's Active trachoma status } & \multirow{2}{*}{$\begin{array}{c}\text { Chi- } \\
\text { Square }\end{array}$} & \multirow[t]{2}{*}{ DF } & \multirow{2}{*}{$\begin{array}{c}\text { P- } \\
\text { Value }\end{array}$} \\
\hline & & & Non Active & Moderate & Sever & & & \\
\hline \multirow[t]{2}{*}{$\operatorname{Sex}$} & Female & $376(49.9)$ & 73.4 & 26.6 & 0 & \multirow[t]{2}{*}{29.647} & \multirow[t]{2}{*}{2} & \multirow[t]{2}{*}{$.000^{*}$} \\
\hline & Male & $378(50.1)$ & 65.3 & 27.2 & 7.4 & & & \\
\hline \multirow[t]{3}{*}{ Agro-climate } & Low & $206(27.3)$ & 72.3 & 22.3 & 5.3 & \multirow[t]{3}{*}{7.59} & \multirow[t]{3}{*}{4} & \multirow[t]{3}{*}{.108} \\
\hline & Medium & $370(49.1)$ & 68.4 & 29.5 & 2.2 & & & \\
\hline & High & $178(23.6)$ & 68.0 & 27.0 & 5.1 & & & \\
\hline \multirow[t]{2}{*}{ Age of the child } & $1-4$ years & $310(41.1)$ & 56.1 & 38.7 & 5.2 & \multirow[t]{2}{*}{43.429} & \multirow[t]{2}{*}{2} & \multirow[t]{2}{*}{$.000 *$} \\
\hline & 5-9 years & $444(58.9)$ & 78.6 & 18.7 & 2.7 & & & \\
\hline \multirow{2}{*}{$\begin{array}{l}\text { Presence of cattle in } \\
\text { the living room }\end{array}$} & Yes & $650(86.2)$ & 66 & 30 & 4 & \multirow[t]{2}{*}{25.289} & \multirow[t]{2}{*}{2} & \multirow[t]{2}{*}{$.000^{*}$} \\
\hline & No & $104(13.8)$ & 90.4 & 7.7 & 1.9 & & & \\
\hline \multirow[t]{3}{*}{ Child spent mostly } & Outside & $232(30.8)$ & 64.2 & 35.8 & 0 & \multirow[t]{3}{*}{96.66} & \multirow[t]{3}{*}{4} & $.000^{*}$ \\
\hline & Home & $331(43.9)$ & 76.4 & 23.6 & 0 & & & \\
\hline & \begin{tabular}{|l|} 
School \\
\end{tabular} & 191(25.3) & 63.4 & 22 & 14.7 & & & \\
\hline Cooking in home & No & $134(17.8)$ & 66.4 & 30.6 & 3 & 1.254 & 2 & .534 \\
\hline & Yes & $620(82.2)$ & 70.0 & 26.1 & 3.9 & & & \\
\hline Washing frequency & Once & $344(45.6)$ & 45.3 & 46.5 & 8.1 & 176.598 & 4 & $.000 *$ \\
\hline & Twice & 278(36.9) & 88.5 & 11.5 & 0 & & & \\
\hline & $\begin{array}{l}\text { More than } \\
\text { twice }\end{array}$ & $132(17.5)$ & 32.6 & 4.2 & 0 & & & \\
\hline Using Soap & Yes & $284(38.7)$ & 72.9 & 22.9 & 4.2 & 3.893 & 2 & .143 \\
\hline & No & $470(62.3)$ & 67.2 & 29.4 & 3.4 & & & \\
\hline Amount of water per & $<20 \mathrm{~L}$ & $142(18.8)$ & 53.5 & 39.4 & 7 & 34.905 & 4 & $.000 *$ \\
\hline & $20 \mathrm{~L}-50 \mathrm{~L}$ & $525(69.6)$ & 70.5 & 26.7 & 2.9 & & & \\
\hline & $>50 \mathrm{~L}$ & $87(11.5)$ & 88.5 & 8 & 3.4 & & & \\
\hline Number of person in & Less than 5 & $181(24)$ & 57.5 & 40.3 & 2.2 & 28.026 & 4 & $.000 *$ \\
\hline house hold & 5 & $126(16.7)$ & 81 & 14.3 & 4.8 & & & \\
\hline & More than 5 & 447 (59.3) & 70.9 & 25.1 & 4 & & & \\
\hline Fly density & More than 5 & $327(43.4)$ & 59.6 & 34.9 & 5.5 & 38.963 & 4 & $.000 *$ \\
\hline & Up to five & $271(35.9)$ & 70.8 & 25.8 & 3.3 & & & \\
\hline & None & $156(20.7)$ & 87.2 & 12.2 & 0.6 & & & \\
\hline & Pit with cover & $326(43.2)$ & 78.2 & 18.7 & 3.1 & 24.666 & 4 & $.000 *$ \\
\hline Garbage disposal & \begin{tabular}{|l}
$\begin{array}{l}\text { Pit without } \\
\text { cover }\end{array}$ \\
\end{tabular} & $30(3.98)$ & 73.3 & 20 & 6.7 & & & \\
\hline & Open & $398(52.8)$ & 61.8 & 34.2 & 4 & & & \\
\hline Toilet facility & Without Pit & $304(40.3)$ & 68.4 & 28.3 & 3.3 & .665 & 2 & .717 \\
\hline & $\begin{array}{l}\text { latrine with } \\
\text { pit }\end{array}$ & $450(59.7)$ & 70 & 26 & 4 & & & \\
\hline House hold working & Others & $196(26)$ & 84.7 & 12.2 & 3.1 & 33.495 & 4 & $.000 *$ \\
\hline status & Governmental & $31(4.1)$ & 74.2 & 19.4 & 6.5 & & & \\
\hline & Farmer & $527(69.9)$ & 63.4 & 32.8 & 3.8 & & & \\
\hline
\end{tabular}

\section{*Significant at $5 \%$}

\subsection{Multiple Ordinal Logistic Regression Analysis}

Multiple Ordinal logistic regressions were fitted based on the chi-square test result of bi-variable analysis. Based on results displayed in Table 4.1 those independent variables that are associated with active trachoma status of rural children at 5\% level significance were selected for multiple ordinal logistic regression analysis. The result displayed in Table 3.1 showed that the ten predictor variables were significantly associated with the active trachoma status.

When the proportional odds model is used in the analysis of ordinal data, the coefficients of the explanatory variables in the model are interpreted as the logarithm of the ratio of the 
odds of the response variable. This means that estimates of this odds ratio, and corresponding confidence intervals, can be easily found from the fitted model. As long as interpretation for categorical (nominal or ordinal) explanatory variables concerned, unlike logistic regression, we do not have the option to directly specify the reference category (last or first,) as SPSS ordinal automatically takes the last category as the reference category. Moreover due to the parallel lines assumption is held, the interpretation of the result obtained by modeling is held, the interpretation of the result obtained by modelling severely or moderately active trachoma versus non-active trachoma and severely active trachoma versus moderately active trachoma.

This study revealed that prevalence of active trachoma among 1-9 years old rural children was $30.6 \%$. Of these, majority $26.9 \%$ had TF, and the rest $3.7 \%$ had TI which confirmed that trachoma is still a disease of public health interest. This result was low as compared to other studies conducted Gonji Kolella district, Zala district and household survey in Amhara Regional State, of Ethiopia [5,6,7]. In contrary other different studies conducted in Leku town, Mojo and Lume districts, and Baso Liben District of Ethiopia show high prevalence of active trachoma as compared to preset study. This may due to difference in geographical, environmental, period of the study and location $[8,9$, and 10$]$.

The results displayed in Table 4.6 show that Child age, Presence of cattle in the living room, Face washing frequency per a day, Number of person sharing room, Fly density and Type of garbage disposal was found to be significant predictors for active trachoma status of children 1-9 years of age in the rural area Kaffa Zone.

The study shows that the estimated odds ratio for age of the child was significant $(\mathrm{OR}=2.085$, $\mathrm{P}<0.002)$ indicate that children in age group (59 years old) was 2.085 times more likely to have severely or moderately active trachoma as compared to children in younger age group (1-4) years old) holding all other variables constant. The odds ratio could be as low as 1.306 and as high as 3.33 with $95 \%$ confidence. This result is in line with a study conducted in Amhara

Regional State, Ethiopia and study conducted in Brazil and Gambian show that a high frequency of trachoma was observed among children aged six to nine years, which corroborates the suggestion of decreased frequency of trachoma with increasing age $[11,12,13]$. In contrary study conducted in Leku town, southern Ethiopia show that age group 1 to 5 years was more venerable for active trachoma. Moreover another global study show that main age group affected with trachoma includes children aged one to five years $[8,14]$

In our study, presence of presence of cattle in the living room, was found out to be significantly associated with children active trachoma status $(\mathrm{P}<0.05)$. The likelihood of severe or moderate active trachoma to children with no cattle in living room is 0.168 times less likely to have severely or moderately active trachoma as compared to those children living with cattle in the living room. This result is consistent with a study done in Ethiopia, south Sudan and Tanzania [15, 7, and 16]. This may due to that flies may breed on animal faces which in turn increase exposure of children to flies.In contrary others study conducted in rural children in Kedida Gamela district Ethiopia show that keeping cattle in the house was found to have a protective effect on child status of active trachoma. Similarly another study in Ethiopia confirmed that neither cattle ownership nor the presence of cattle in the village has a major role in the size of the fly population; instead, the major determinant seems to be the way in which the cattle were kept $[17,18]$.

From Table 4.6 we can also observe that children face washing frequency per dayalso significantly related with the active trachoma status of children. Children who wash their face more than twice per day are 3.34 times more likely to have severely or moderately active trachoma as compared to children who wash their face once per day holding all other variables constant. The odds ratio could be as low as 1.55 and as high as 7.21 with $95 \%$ confidence. This result is consistent with other studies indicate that as the frequency of washing face decreases the odds of having low trachoma level decreases, which means ensuring facial and hand cleanliness using water to keep children's face clean throughout the day are important component of trachoma prevention $[17,19]$. This may due to unclean face attracts flies, and flies are important mechanical vectors for the transmission of trachoma [20]. 
Application of Ordinal Logistic Regression Analysis in Determining Risk Factors of Active Trachoma among Rural Children of Aged 1-9 Years Old in Kaffa Zone, South West Ethiopia

Table4.6. Ordinal Logistic Regression Results of Children's aged 1-9 years oldActive trachoma status according to selected independent variables, Kaffa Zone, South-West Ethiopia (2018).

\begin{tabular}{|c|c|c|c|c|c|c|c|c|}
\hline \multirow[t]{2}{*}{ Parameter } & \multirow[t]{2}{*}{$\widehat{(\beta)}$} & \multirow[t]{2}{*}{ S.E } & \multirow[t]{2}{*}{ Wald } & \multirow[t]{2}{*}{ df } & \multirow[t]{2}{*}{ Sig. } & \multirow{2}{*}{$\begin{array}{l}\text { Odds } \\
\text { Ratio }\end{array}$} & \multicolumn{2}{|c|}{$\begin{array}{l}\text { 95\% Confidence } \\
\text { Interval }\end{array}$} \\
\hline & & & & & & & $\begin{array}{l}\text { Lower } \\
\text { Bound }\end{array}$ & $\begin{array}{l}\text { Upper } \\
\text { Bound } \\
\end{array}$ \\
\hline \multicolumn{9}{|c|}{ Age $($ Ref.=5-9 years old $)$} \\
\hline $1-4$ years old & .735 & .239 & 9.46 & 1 & $.002 *$ & 2.085 & 0.267 & 1.203 \\
\hline \multicolumn{9}{|l|}{ Sex (Ref.=Female) } \\
\hline Male & 0.265 & 0.534 & 0246 & 1 & 619 & 1.303 & 0.267 & 1.203 \\
\hline \multicolumn{9}{|c|}{$\begin{array}{l}\text { Presence of cattle in the living room }(\mathrm{Ref}= \\
\text { Yes) }\end{array}$} \\
\hline No & -1.781 & .510 & 12.20 & 1 & $.000^{*}$ & .1685 & -1.781 & -3.781 \\
\hline \multicolumn{9}{|c|}{$\begin{array}{l}\text { Face washing frequency per a day }(\text { Ref.= } \\
>=2)\end{array}$} \\
\hline Once & 1.206 & .393 & 9.417 & 1 & $.000^{*}$ & 3.340 & .436 & 1.976 \\
\hline Twice & 2.349 & 1.867 & 1.583 & 1 & $.208^{*}$ & 10.475 & 1.311 & 6.01 \\
\hline \multicolumn{9}{|c|}{$\begin{array}{l}\text { water fetch per a day(Ref.=more than } 50 \\
\text { litters) }\end{array}$} \\
\hline less than 20 litters & 1.325 & 2.456 & 1.463 & 1 & .589 & 3.762 & 3.489 & 6.139 \\
\hline $20-50$ litters & .024 & .672 & .001 & 1 & .971 & 1.024 & -1.293 & 1.342 \\
\hline \multicolumn{9}{|c|}{$\begin{array}{l}\text { Number of person sharing room } \\
\text { (Ref.=more than 5) }\end{array}$} \\
\hline Less than five & -3.676 & 1.130 & 10.58 & 1 & $.001 *$ & .025 & -5.891 & -1.461 \\
\hline Five & -1.710 & .813 & 4.424 & 1 & $.035^{*}$ & .181 & -3.303 & -0.117 \\
\hline \multicolumn{9}{|c|}{ Fly density (Ref.=none) } \\
\hline Up to five & 1.035 & .493 & 4.41 & 1 & $.036^{*}$ & 2.817 & .068 & 2.001 \\
\hline More than five & .766 & .266 & 8.29 & 1 & $.004 *$ & 2.150 & .245 & 1.287 \\
\hline \multicolumn{9}{|c|}{ Child spent mostly (Ref.= at school) } \\
\hline Playing on street & -2.450 & 2.366 & 1.072 & 1 & .300 & 0.086 & -7.087 & -2.187 \\
\hline Home & -2.812 & 3.743 & .564 & 1 & .453 & 0.060 & -10.148 & -4.524 \\
\hline \multicolumn{9}{|c|}{ House hold working status (Ref.=farmer) } \\
\hline Governmental & .306 & .597 & .263 & 1 & .608 & 1.358 & .864 & 1.476 \\
\hline Others & .473 & 1.959 & .058 & 1 & .810 & 1.605 & 3.367 & 4.313 \\
\hline \multicolumn{9}{|c|}{ Garbage disposal (Ref.=Open) } \\
\hline pit with cover & -3.483 & .479 & 52.87 & 1 & $.000 *$ & .031 & -4.422 & -2.544 \\
\hline pit without cover & -2.888 & .560 & 26.59 & 1 & $.000 *$ & .056 & -3.986 & -1.790 \\
\hline
\end{tabular}

*Significant at $5 \%$

The model also show that household garbage disposal method was significantly associated with rural children active trachoma status. Children from household use pit with cover as garbage disposal method was 0.031 times less likely to have severely or moderately active trachoma as compared to children with no fly on their face [5, 21 and 22]. Unlike previous studies reporting prevalence of trachoma associated type of toilet facility and where the child spent mostly) but present study show that there is no significance association child active trachoma status with toilet facility and child status. This may due to interaction effect not considered in present study $[11,17]$.

This study also indicated that fly density around child face is significantly related with the active trachoma status of children $(\mathrm{OR}=2.15,95 \% \mathrm{CI}$ : $1.070-7.396)$. Children with five or more flies on the face are 2.150 times more likely to have severely or moderately active trachoma as compared to children with no fly on their face. The result is consistent with as study conducted in the Gurage zone of central Ethiopia reveled that density of 'eye seeking' flies is also high in areas where the prevalence of active trachoma is very high [23].

\section{CONCLUSIONS AND RECOMMENDATION}

In conclusion, this study explored the association using multiple logistic regressions hence the result showed that Child age, Cattle in the house, Face washing frequency per a day, Number of person sharing room, Fly density and Type of garbage disposal were most important determinants for active trachoma status of children 1-9 years of age in the rural area Kaffa Zone. 
From this study we conclude that increase washing frequency per day and use pit with cover for garbage disposal and living in separate room with cattle was protect a child from active trachoma. In contrary younger children, living in crowded environment and having Fly around child's face increase a risk of active trachoma. The current study thus helps provide a better understanding of the events linked to these diseases at the local level and the basis for establishing specific programs for their control.

Trachoma is an entirely preventable and treatable disease. As such, blinding trachoma should be eliminated. This study support continued efforts to implement the face cleanness and environmental improvement components of the WHO safe strategy for combating trachoma. As different past studies have also show this study also recommend that improvements in hygiene, separating living and cattle rooms, always wash face and making environment clean to are the measures needed to reduce the magnitude of active trachoma.

Consequently, efforts should be applied on improving face washing habit of children to reduce the magnitude of the disease in them as they are the reservoir of the causative agent. It is also important that efforts to improve their hygiene are coupled with health education programs to prevent trachoma. So, trachoma is still a major health concern among children age 1-9 years in the study area. Both government and non-government organizations, who are working in elimination blinding trachoma, need to consideration the hygiene and garbage disposal methods in their preventive strategies.

\section{ACKNOWLEDGEMENTS}

I would like to express my special gratitude to all manager of health office of Kaffa zone for their important directions, preparing the available data, encouragement and support from the initial to final level during this study. My special thanks have goes to Mizan-Tepi University, especially Institute of Research and Community Development Support office for giving us a chance for completing this community based research and financial support.

\section{REFERENCES}

[1] World Health Organization. Report of the 3rd Global Scientific meeting on trachoma, Johns Hopkins University, Baltimore, MD, 19-20 July 2010. Geneva:

[2] World Health Organization, 2010 Thomson I. A clinic based survey of blindness and eye diseases in Cambodia. British Journal of Ophthalmology 1997; 81: 578-580.

[3] Alene GD, Abebe S. Prevalence of risk factors for trachoma in a rural locality of north-western Ethiopia. East Afr Med J. 2000; 77(6):308-12

[4] O'Connell A. A. (2000): Methods for modelling ordinal outcome variables: Measurement and Evaluation in Counselling and Development: pp 170-193, Ophthalmic. 1999; 117:974, Ophthalmology, 1987; 71: 873876.

[5] Nigus A, Berhe R, Gedefaw M. Prevalence and associated factors of active trachoma among children aged 1-9 years in rural communities of Gonji Kolella district, West Gojjam Zone, North West Ethiopia. BMC Res Notes 2015; 8: 641.

[6] Mengistu K, Shegaze M, Woldemichael K, et al. Prevalence and factors associated with trachoma among children aged 1-9 years in Zala district, Gamo Gofa Zone, Southern Ethiopia. Clin Ophthalmol 2016; 10: 16631670.

[7] Ngondi, J.,Matthews, F., Reacher, M, Onsarigo, A, Matende, I.Baba, S.Brayne,C., Zingeser, J.,

[8] Emerson, P., 2007. Prevalence of risk factors and severity of active trachoma southern Sudan: an ordinal analysis. Am. J. Trop. Med. Hyg77126-132

[9] Teshome A, Dawit J. Prevalence and distribution of active trachoma among children 1-9 years old at Leku town, southern Ethiopia. Curr Pediatr Res 2017; 21 (3): 507-513

[10] Ketema K, Tiruneh M, Woldeyohannes D, Muluye D. Active trachoma and associated risk factors among children in Baso Liben District of East Gojjam, Ethiopia. BMC Public Health. 2012; 12:1105.

[11] Yalew KN, Mekonnen MG, Jemaneh AA. Trachoma and its determinants in Mojo and Lume districts of Ethiopia. Pan Afr Med J 2012; 13: 8.

[12] Jeremiah N, Teshome G and Estifanos B, Risk factors for active trachoma in children and trichiasis in adults: a household survey in Amhara Regional State, Ethiopia. Transactions of the Royal Society of Tropical Medicine and Hygiene (2008) 102, 432-438

[13] Luna EJA, Lopes MFC, Medina NH, Favacho $\mathrm{J}$, Cardoso MRA, Prevalence of trachoma in school children in Brazil. Ophthalmic Epidemiology. 2016; 23:360 \pm 365 . https://doi. org/10.1080/09286586.2016.1244274PMID: 27824506

[14] Grassly NC, Ward ME, Ferris S, Mabey DC, Bailey RL. The natural history of trachoma infection and disease in a Gambian cohort with frequent followup. PLoSNeglTropDis.2008; 
2:e341.https://doi.org/10.1371/journal.pntd.000 0341PMID: 19048024

[15] Mariotti SP,Pascolini D,Rose- Nussbaumer J. Trachoma: global magnitude of a preventable cause of blindness.Br J Ophthalmol 2009;93: 563+568.https://doi.org/10.1136/bjo.2008.1484 94PMID: 19098034

[16] Cumberland P, Hailu G, Todd J. Active trachoma in children aged three to nine years in rural communities in Ethiopia: prevalence, indicators and risk factors. Trans R Soc Trop Med Hyg. 2005; 99:120-127.

[17] Polack S, et al. The relationship between prevalence of active trachoma, water availability and its use in a Tanzanian village. Transactions of the Royal Society of Tropical Medicine and Hygiene. 2006; 100(11):10751083.

[18] Essey Kebede Muluneh, Temesgen Zewotir, and Zerihun Bekele.Rural children active trachoma risk factors and their interactions. Pan Afr Med J. 2016; 24: 128.

[19] DE Sole G. Impact of cattle on the prevalence and severity of trachoma. British Journal of Ophthalmology. 1987; 71:873-876.

[20] Stephanie, O. and Paul, E. (2012) How communities can control trachoma without a big budget. Journal of Com- munity Eye Health, 25, 80-81

[21] International Center for Eye Health (ICEH), 2007. London School of Hygiene \& Tropical Medicine, UK.

[22] Alemayehu M, Koye DN, Tariku A, et al. Prevalence of active trachoma and its associated factors among rural and urban children in Dera Woreda, northwest Ethiopia: A comparative cross-sectional study. Bio Med Res Int 2015: 8 .

[23] Mesfin MM, de la Camera J, Tareke IG, et al. A community-based trachoma survey: Prevalence and risk factors in the Tigray region of northern Ethiopia. Ophthalmic Epidemiol 2006; 13:173-181

[24] Taye, A., Alemayehu, W., Melese, M., Geyid, A., Mekonnen, Y., Tilahun, D., Asfaw, T., 2007. Seasonal and altitudinal variationsin fly density and their association with the occurrence of trachoma, in the Gurage zone of central Ethiopia. Ann. Trop. Med. Parasitol. $101,441-448$

[25] Central Statistics Authority. 2011 census report for the SNNPR, 1996. Addis Ababa, Ethiopia.

Citation: Tesfaledet Tsegay, Yewulshet Mengistu,Tadesse Nigussie. Application of Ordinal Logistic Regression Analysis in Determining Risk Factors of Active Trachoma among Rural Children of Aged 1-9 Years Old in Kaffa Zone, South West Ethiopia. ARC Journal of Public Health and Community Medicine.2019; 4(1):20-28. DOI: dx.doi. org/ 10.20431/2456-0596.0401003.

Copyright: (c) 2019 Authors. This is an open-access article distributed under the terms of the Creative Commons Attribution License, which permits unrestricted use, distribution, and reproduction in any medium, provided the original author and source are credited. 